\title{
The Impact of Hospital Accreditation on Nurses' Perceptions of Quality of Care?
}

\section{Tejo Trisno, Agit Pratama Putra, and Sena Wahyu Purwanza}

Faculty of Nursing, Universitas Airlangga, Surabaya, Indonesia

\begin{abstract}
Introduction: Accreditation is the recognition of the quality of services that have met the National Hospital Accreditation Standards. In implementing hospital accreditation , it covers patient safety goals, patient-focused service standards, hospital management standards, national programs and integration of health education in hospital services. How is the impact of hospital accreditation on the quality of care, especially nursing services in accordance with the perceptions and attitudes of nurses in hospitals. Therefore, it is necessary to identify the impact of applying hospital accreditation in accordance with nurses' perceptions and attitudes towards nursing services.
\end{abstract}

Methods: For this reason, articles data with a for publication from 20082018 are needed, of the 418 systematic literature articles taken from Scopus, Science direct, and Proquest. There are 15 articles chosen to search for literature with keywords; the impact of accreditation on nurses' perceptions and attitudes about the quality of care.

Results: Five of the 15 articles that fit the design criteria that address the impact of hospital accreditation according to nurses' perceptions and attitudes in improving nursing services.

Conclusion: The study results show that hospital accreditation make a nurses perception the quality of care. Quality of care is the one of impact from hospitals accreditation. Nurses in accredited hospitals feel a higher level of quality of health services.

\section{ARTICLE HISTORY}

Received: Dec 26, 2019

Accepted: Dec 31, 2019

\section{KEYWORDS}

accreditation; quality service; hospital; nursing service; attitude; quality of care

\section{CONTACT}

Tejo Trisno

$\triangle$ tejo.trisno-2018@fkp.unair.ac.id $\Xi^{\circ}$ Faculty of Nursing, Universitas Airlangga, Surabaya, Indonesia

Cite this as: Trisno, T., Putra, A.P., \& Purwanza, S.W. (2019). The Impact of Hospital Accreditation on Nurses' Perceptions of Quality of Care?. Jurnal Ners, 14(3si), 408-412. doi:http://dx.doi.org/10.20473/in.v14i3(si).17218

\section{INTRODUCTION}

Accreditation, defined as public recognition by National Health Accreditation Commission accreditation standards achievement by Health Organizations, through assessment by external and independent survivors appointed by the ministry of health (Reisi, Raeissi, Sokhanvar, \& Kakemam, 2019). Developing countries often use hospital accreditation to ensure patient quality and safety. However, the adoption of hospital accreditation standards is considered too demanding in the field of health services. In addition, the empirical literature on the benefits of accreditation is rare and this is the first empirical interrupted time series analysis designed to examine the impact of health accreditation on measures of hospital quality (El-jardali, Jamal, Dimassi, Ammar, \& Tchaghchaghian, 2008). The National Hospital Accreditation Standard is a method for viewing and assessing the quality of health care organizations using external surveyors and published standards.

This is often compared to an internal review process where members of the organization develop their own methods and standards to assess quality. There is little evidence available to verify which of the two forms of review have an impact on clinical outcomes and patient care. The accreditation process focuses more on risk management and patient safety than the previous steps to ensure the level of compliance with standards (Griffith, 2018). Patient safety is important to consider in health care. Thus, various programs are included by health institutions to monitor their services including patient safety procedures. Accreditation is one program to monitor health services and evaluation processes that are internationally and nationally recognized that are used to assess, promote, and ensure quality and 
efficient patient care and patient safety (Top \& Tekingündüz, 2015).

Accreditation is increasingly being applied as a tool for the government to regulate and guarantee the quality of service quality and patient safety (Alswat et al., 2017). Hospitals must implement, develop and evaluate an effective, sustainable quality assessment and performance improvement program in all hospitals, based on information systems (SIM RS). Hospital management must ensure that the program improves patient quality and safety in hospital services, to involve all hospital departments and services (Bahrami, Chalak, Montazeralfaraj, \& Dehghani Tafti, 2014). Improving market orientation and patient safety has become a major concern for nursing management. For that nurses, must build a climate of improving quality and patient safety is the key to improving nursing quality (Nomura, Pruinelli, Da Silva, Lucena, \& Almeida, 2018).

Health care facilities are always associated with increased patient safety risks. In the past, the functions of risk management and quality improvement often operated separately in health service organizations. In addition, each individual who is also responsible for each function has a different reporting path. Nurses' perceptions of improving quality and patient safety are important in health care organizations. In addition, some hospitals have admitted that patients will receive care with guaranteed safety. High-quality care is very important to protect the institution's financial assets and also to lose, so it is very important to have risk and management plans. In this case, risk management and patient safety professionals correlate in close working relationships (Greenfield, Pawsey, \& Braithwaite, 2011).

The nurse is responsible for ensuring that caring for the patient with safe care, no danger has occurred. Nurses have an important role in patient safety and reduce medical errors. In the past few decades, patient safety has become a high priority health system problem, because of the high potential for side effects in health facilities because it shows the challenge of a weak patient safety culture, in hospitals. Therefore, this problem must be integrated into all policy makers and managerial initiatives in our health system, as a top priority (Zyoud et al., 2019). Nurses as the largest group of healthcare providers in offering direct patient care. The purpose of this study was to describe nurses 'perceptions of the culture of patient safety after hospital accreditation, the correlation between nurses' perceptions of hospital accreditation and improving the quality of nursing services.

\section{MATERIALS AND METHODS}

This systematic review is carried out following the steps based on the PRISMA Statement, namely (Reisi et al., 2019) Formulating research questions, (Eljardali et al., 2008) Choosing relevant research terms and formulating search phrases in consultation with information specialists in the health sciences, (Griffith, 2018) Planning a search strategy, (Top \& Tekingündüz, 2015) Approve inclusion and exclusion criteria, (Alswat et al., 2017) Conduct systematic searches in electronic databases, (Bahrami et al., 2014) Select appropriate research articles and [7] Conduct quality assessments of studies chosen for review (Moher et al., 2009). Search Strategy and Inclusion Criteria Systematic searches were collected from ProQuest (347,327 journals),

Scopus (418 journals), and ScienceDirect (592 journals). Search is done using a combination, using Boolean terms and quotes to qualify for this study, this article uses a cross-sectional method, one article uses multiple regression analysis, one article uses study intervention and one article uses descriptive research design methods and reviewed design literature and answered research questions. Articles that are not relevant to the research questions or not related to nurses' perceptions related to the patient safety culture and hospital accreditation era will be excluded from this study (as shown in Figure 1). In the screening process, we get 15 full text articles that meet the requirements of the search key words that match those included in the study, and also according to the purpose of this review.

Finally, seven $(n=5)$ articles are selected from this selection process. To sharpen the selection process and find the expected objectives in this literature review, we limit the articles in various electronic databases from various countries that have a diversity of nurse characteristics and various hospital policies related to the patient safety culture. It aims to get the latest information from the topic of nurses' perceptions of the patient safety culture in the era of hospital accreditation, because in this era, it cannot be denied that in all regions of the world, hospital accreditation is one of the requirements in quality hospital service ratings . In all of these studies, the study sample was nurses, according to the purpose of this article, and looked at whether there were significant changes in nurses' perceptions of patient safety culture in the accreditation era, because patient safety was the target of assessment to obtain accredited hospital status (as shown in Table 1 ) .

\section{RESULTS}

Based on the research subject we found the number of respondents was 5311 of nurses, 12.112 survey from patients record, 30 staff of health care and director hospitals as 638 respondents. Based on the location of the study we found all of studies were conducted at the hospitals. Based on the research design, we found thirteen quantitative studies with the type of 9 cross sectional, 2 descriptive correlation, 2 comparation and 2 types of retrospective. For data sources, the questionnaire is the instrument used from the thirteen articles and intervention was conducted from the two articles. We identified several instruments used to measure perception the 
Records identified through database searching $(n=347327)$
Additional records identified through other sources $(\mathrm{n}=1110)$

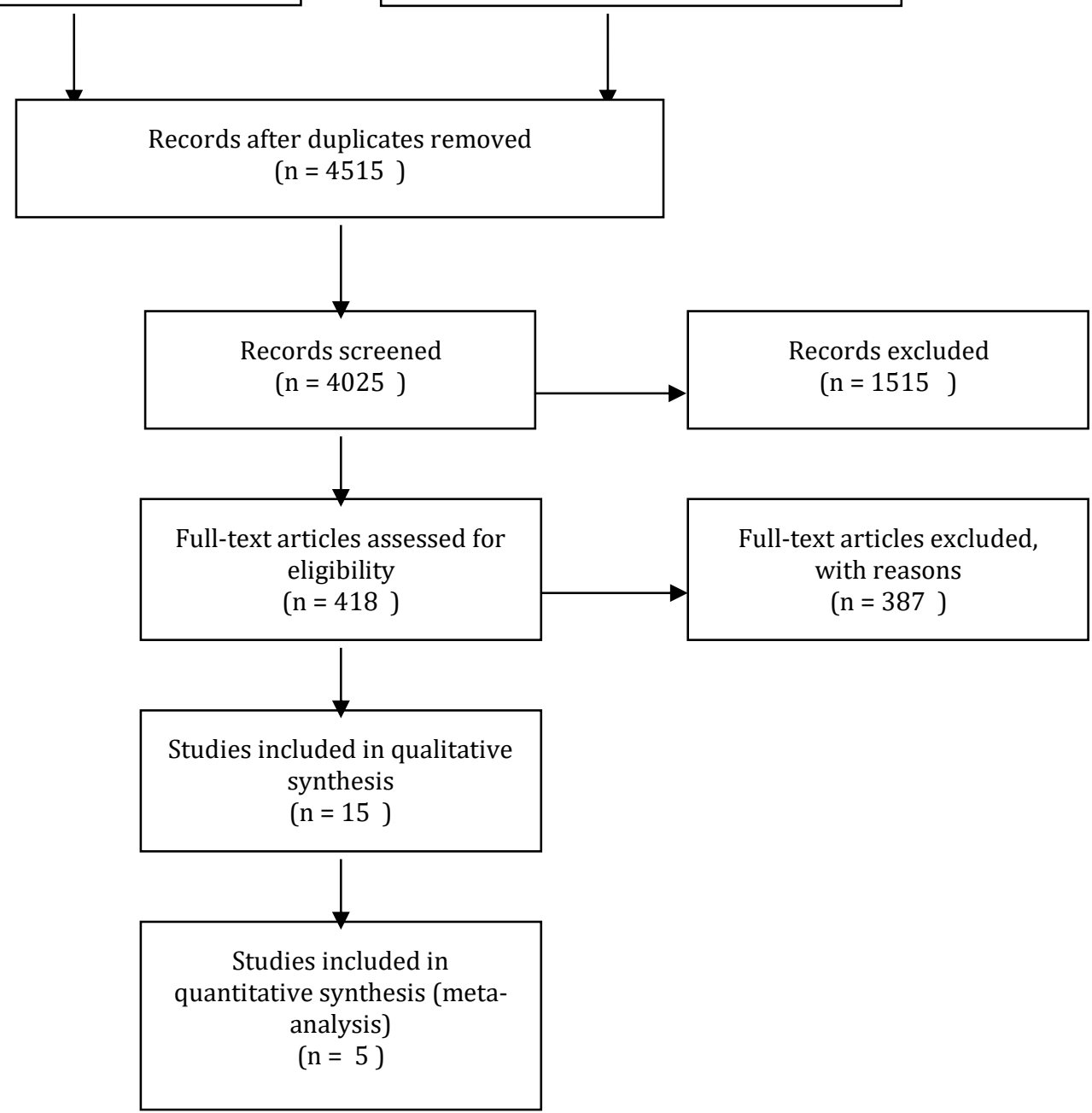

Figure 1 PRISMA flow chart (Moher et al. 20-09).

nurses about outcomes of hospitals accreditation to improving quality of care.

From the results of a review of fifteen articles it was found that nurses perceived an improvement of quality care in hospitals as an outcome of accreditation. In terms of the benefits of hospitals accreditation (Reisi et al., 2019), nurses' perspectives, hospital managers can facilitate accreditation program implementation through financial support, strengthening of commitment and accountability, solving human resource issues, and stop current programs overlapping and revising the accreditation program. According to nurses perception that accreditation standards should also be revised regularly to ensure that they comply with the most recent worldwide standards and continue to be relevant (El-jardali et al., 2008), the impact of hospital accreditation is improve the patient safety level. Nurses' perceptions of patient safety appear to be essential. Nurses are important for the improvement of the patient safety culture in health care organizations. Accreditation has an overall statistically significant improvement in the perception of the culture of patient safety (Griffith, 2018; Nomura et al., 2018), Participants' perception of safety climate was positively correlated with their attitude toward medication error reporting; this correlation strengthened following completion of the program (Alswat et al., 2017), Nurses perceptions that JCI accreditation may help health systems enhance the awareness and ability to prevent MAEs and achieve successful quality improvements (Bahrami et al., 2014). Hospital accreditation has a positive impact on quality results especially on the quality of care provided to patients and patient satisfaction (Greenfield et al., 2011), nurses have an perception that hospital accreditation had a significant impact on hospitals' IC infrastructure and performance and accreditation helps teams review their work and improve their ideas about what they have done ... it clarifies things for staff and gives a sense of direction, clarify issues and be constructive 
and offer ideas for improvement, felt comfortable and confident to approach the surveyors but they were pressured by time to move on ... much more time for discussion is necessary, the overall timetable is rushed and often compromised (Sekimoto et al., 2008; Yildiz \& Kaya, 2014). Interventions that help hospital administration and managers to provide more supportive leadership may facilitate safety climate improvement. Hospitals and their units should develop more friendly and intimate working environments that remove nurses' fear of penalties. Administration and managers should support nurses who report their own errors (Zyoud et al., 2019), the nurses perception that hospital accreditation improvement in the nursing documentation. Educational interventions performed by nurses led to a positive change that improved nursing documentation and, consequently, better care practices (Al-Awa et al., 2012).

\section{DISCUSSION}

The perception of nurses on hospital accreditation outcomes is an increase teamwork and productivity. There needs to be a reward, recognition, leadership and commitment to the accreditation of hospitals so that it can enchance cooperation in improving patient safety (Reisi et al., 2019). The impact of hospital accreditation is improve the patient safety. Accreditation has an overall advantage over certification in clinical leadership and review but some of these results are statistically significant improvement in the perception of the culture of patient safety. Where both systems, active on their own, show a positive relationship with quality management, the effect in combinations seems to be bigger and more significant. The determination and evaluation of the patient safety culture level in hospitals should be viewed as a continuous process where a need for continuous improvements in the hospital patient safety culture exists. To improve the patient safety level, nurses' perceptions of patient safety appear to be essential. Nurses are important for the improvement of the patient safety culture in health care organizations. Moreover, some hospitals have recognized that providing (Griffith, 2018). Nurses' perceptions of the patient safety culture are influenced by many factors including internal nurse factors and external or environmental factors. Internal factors are competency and position in the organization and also competence consists of age, level of education, and clinical experience. And it is classified as an external factor that influences nurses' perceptions of the patient's safety culture: leadership, hospital policy, teamwork, management support, open communication, promotion, and appreciation. Hospital accreditation had a significant impact on performance and accreditation helps teams review their work and improve their ideas (Sekimoto et al., 2008). Nurses' Perceptions themselves had enough staff and resources to provide quality nursing care, and had good nurse-doctor relationships and collegial Presence of nursing leadership visible and competent all factors that are strongly related to the assessment of the safety of patient care in their workplace. The perception of having enough staff and resources might not be consistent with the patient's ratio: actual staff, but it seems to be an important factor related to how nurses see patient safety in their hospital ward or unit. This is a fact that nurses are the largest community in an accredited hospital or not, and the main point is that nurses are the spearhead of hospital services that interact more frequently with patients. Thus, the patient safety culture must be the commitment of the nurses. In accreditation, patient safety is one of the objectives assessed, and is the main prerequisite that hospitals must meet various size requirements. There is a significant increase in nurses' perceptions of the patient safety culture in the process and after hospital accreditation. Hospital accreditation has a positive impact on quality especially on the quality of care provided to patients and patient satisfaction (Sekimoto et al., 2008). Hospital accreditation make a nurses have a safety culture rooted in their awareness, it will be a more point in the process of improving the quality of hospital services, of course. Nurses part of professional caregivers to patients and the most energy in hospitals in managing patients comprehensively will continue to increase awareness in improving the quality and safety of patients in hospitals.

\section{CONCLUSION}

The study results show that hospital accreditation make a nurses perception the quality of care. Quality of care is the one of impact from hospitals accreditation. Nurses in accredited hospitals feel a higher level of quality of health services. Nurses' perceptions of the patient safety culture are influenced by leadership, commitment, and supporting strategic quality planning, education and training. Another influence of the factors is the management of quality and data use compared to their counterparts in non-accredited hospitals. In accredited hospital perception of safety climate was positively correlated with their attitude toward medication error reporting. Strengthening the safety climate in the workplace is an important step towards improving patient safety. At the level of the patient safety competency dimension, teamwork and communication are significantly related to the perceived safety climate. Therefore, increasing nurse safety competencies, with an emphasis on teamwork and effective communication, can contribute to building a strong safety culture. Because there was a lack in the reviewed studies used the cross-sectional and correlation, well-designed such as qualitative should be conducted to more objectively evaluated the fenomena of nurses perception about impact of hospital accreditation on quality of care. 


\section{REFERENCES}

Al-Awa, B., Al Mazrooa, A., Rayes, O., El Hati, T., Devreux, I., Al-Noury, K., ... El-Deek, B. S. (2012). Benchmarking the post-accreditation patient safety culture at King Abdulaziz University Hospital. Annals of Saudi Medicine. https://doi.org/10.5144/0256-4947.2012.143

Alswat, K., Abdalla, R. A. M., Titi, M. A., Bakash, M., Mehmood, F., Zubairi, B., ... El-Jardali, F. (2017). Improving patient safety culture in Saudi Arabia (2012-2015): Trending, improvement and benchmarking. BMC Health Services Research. https://doi.org/10.1186/s12913-017-2461-3

Bahrami, M. A., Chalak, M., Montazeralfaraj, R., \& Dehghani Tafti, A. (2014). Iranian nurses' perception of patient safety culture. Iranian Red Crescent Medical Journal. https://doi.org/10.5812/ircmj.11894

El-jardali, F., Jamal, D., Dimassi, H., Ammar, W., \& Tchaghchaghian, V. (2008). The impact of hospital accreditation on quality of care: Perception of Lebanese nurses. International Journal for Quality in Health Care. https://doi.org/10.1093/intqhc/mzn023

Greenfield, D., Pawsey, M., \& Braithwaite, J. (2011). What motivates professionals to engage in the accreditation of healthcare organizations? International Journal for Quality in Health Care. https://doi.org/10.1093/intqhc/mzq069

Griffith, J. R. (2018). Is It Time to Abandon Hospital Accreditation? American Journal of Medical Quality, 33(1), 30-36. https://doi.org/10.1177/1062860617707578

Moher, D., Liberati, A., Tetzlaff, J., Altman, D. G., Altman, D., Antes, G., ... Tugwell, P. (2009). Preferred reporting items for systematic reviews and meta-analyses: The PRISMA statement. Annals of Internal Medicine, Vol. 151, pp. 264-269. https://doi.org/10.7326/00034819-151-4-200908180-00135
Nomura, A. T. G., Pruinelli, L., Da Silva, M. B., Lucena, A. D. F., \& Almeida, M. D. A. (2018). Quality of Electronic Nursing Records: The Impact of Educational Interventions During a Hospital Accreditation Process. CIN - Computers Informatics Nursing. https://doi.org/10.1097/CIN.0000000000000 390

Reisi, N., Raeissi, P., Sokhanvar, M., \& Kakemam, E. (2019). The impact of accreditation on nurses' perceptions of quality of care in Iran and its barriers and facilitators. International Journal of Health Planning and Management. https://doi.org/10.1002/hpm.2642

Sekimoto, M., Imanaka, Y., Kobayashi, H., Okubo, T., Kizu, J., Kobuse, H., ... Yamaguchi, A. (2008). Impact of hospital accreditation on infection control programs in teaching hospitals in Japan. American Journal of Infection Control. https://doi.org/10.1016/j.ajic.2007.04.276

Top, M., \& Tekingündüz, S. (2015). Patient Safety Culture in a Turkish Public Hospital: A Study of Nurses' Perceptions About Patient Safety. Systemic Practice and Action Research. https://doi.org/10.1007/s11213-014-9320-5

Yildiz, A., \& Kaya, S. (2014). Perceptions of nurses on the impact of accreditation on quality of care: A survey in a hospital in Turkey. Clinical Governance. https://doi.org/10.1108/CGIJ-072013-0021

Zyoud, S. H., Khaled, S. M., Kawasmi, B. M., Habeba, A. M., Hamadneh, A. T., Anabosi, H. H., ... Al-Jabi, S. W. (2019). Knowledge about the administration and regulation of high alert medications among nurses in Palestine: A cross-sectional study. $B M C$ Nursing. https://doi.org/10.1186/s12912-019-0336-0 